$\xi_{p=1}$

\title{
Effect of a construction educational protocol on nurses' knowledge, performance and its effect on patient satisfaction undergoing cardiac catheterization
}

\author{
Samia Eaid Elgazzar ${ }^{1 *}$, Lamiaa Ismail Keshk ${ }^{2} * *$ \\ ${ }^{1}$ Lecturer at Medical Surgical Nursing Department, Faculty of Nursing, Port Said University, Egypt \\ ${ }^{2}$ Assistant Professor in Nursing administration Department, Faculty of Nursing/Helwan University Egypt \\ *Corresponding author E-mail: adamramy36@yahoo.com
}

\begin{abstract}
Cardiac Catheterization is a life-threatening health problem, which needs standardized intervention policies, as well as it requires health provider to be skillful and high qualify to attain highest effect of management. This study aimed to investigate the effect of a construction educational protocol on nurses' knowledge, performance and its effect on patient satisfaction undergoing cardiac catheterization.

Methods: This quasi-experimental study was conducting in catheterization, intensive care and cardiac care unit at general Port Said hospital in Port Said city - Egypt including all nurses were worked at those units (51) and all patients admitted to cardiac catheterization unit within 6 month. Data was collected through Socio -Demographic data sheet, structured questionnaire to assess knowledge, observational checklist to assess nurses' performance and tools to assess patient sociodemographic data and patient satisfaction.

Results: There was increase nurses knowledge and performance in the post educational protocol in all domains of care regarding cardiac catheterization. While, majority of patients were satisfied for the nursing care before, during and post cardiac catheterization procedure that rendered by nurses that have educational protocol. Also, strong positive correlation between nurses' knowledge and patient satisfaction at post educational protocol with statistical significant differences.

Recommendation: updating knowledge and performance of nurses through implementation continuing educational protocol about cardiac catheterization; strict observation of nurses' performance when caring for cardiac catheterization patients and provision of guidance to improve of satisfaction.
\end{abstract}

Keywords: Educational Protocol; Knowledge; Performance; Satisfaction; Cardiac Catheterization.

\section{Introduction}

Cardiac Catheterization (CC) is that procedure that considered golden method for the decision, diagnosis, and dealing with cardiac diseases. Cardiac catheterization procedure is a further important process for assessing and gaining more data about the anatomy and physiology of the cardiac cavities, valves and coronary arteries. This procedure too include studies of the left and right sides of the heart and coronary arteries (Mohammed et al., 2013, Ahmed, 2015). Coronary Angiography (CA) is one of the most common and the best method for diagnosis of coronary artery diseases (Moradi \& Adib-Hajbaghery,2015).Recently cardiac catheterization procedure takes a wide range because of its advantages at little time for patients with heart disease such as Ischemic Heart Disease (IHD), Coronary Artery Disease (CAD), congenital heart disease and valvular heart diseases. So assessing Quality of health care services will determine the degree to which health services for patients with cardiac catheterization and populations increase the likelihood of desired health outcomes and are consistent with current professional knowledge (Kern, 2011).

The ability to satisfy patients is vital for many reasons. It is mainly helpful for hospitals to establish a patient who is oriented towards quality health services rather than focusing only on the patient's disease. Improvement in the service quality involuntarily uplifts the reputation gained by the health care institution. Patients' satisfaction is also a valuable competitive tool, to increase staff motivation. (Dayasiri, 2010, Mahdi \& Mohammad 2016).

Satisfaction is achieved when the patient's perception of the quality of care and services that they receive in healthcare setting has been positive, satisfying, and meets their expectations. A satisfied patient will recommend center's services to friends and family. While a satisfied patient may express that satisfaction to four or five people, a dissatisfied one on the other hand will complain to twenty or more. Also, satisfied patients are more likely to co-operate with treatment. Measures of patient satisfaction are used to compare health care educational protocols, to evaluate quality of care, and to identify which aspects of a service need improvement. In addition, patient evaluations can help to educate medical staff about their achievements as well as their failure, assisting them to be more responsive to their patients' needs (Al Sharif, 2008).

So, Nurses role is an important in advancement of the patient's information before invasive the procedure (Jamshidi et al., 2009). As a result of information, patients experience stress, apprehension and accordingly hemo-dynamic unsteadiness in response to an insertion of catheter procedures. Besides, as a result of lengthy bed 
ridden in one position after cardiac catheterization, report the patient's feelings of altered comfort and intolerance (Ruffinengo, 2009). Also, the information of the patient's may low their psychological disturbance significantly reduce the nursing effort, decrease the hospital length stay, and help the nurses and patients satisfaction, well-being and tolerance related to an percutaneous procedure (Chair et al., 2004).There are numerous approaches of patients' teaching as oral knowledge, written information, audiotapes, booklets and video information (Philli pe et al., 2006). But is a method to be used for patients' teaching is still unidentified. In spite of these procedure or method of cardiac catheterization, the verbal knowledge by nurses and physicians is the mutual routine for patient's information before coronary angioplasty in almost hospitals (Steffenino et al 2007).

\subsection{Significance of the study}

Coronary vascular diseases (CVDs) are the number one cause of death globally: more people die annually from CVDs than from any other cause. An estimated 17.7 million people died from CVDs in 2015, representing $31 \%$ of all global deaths. Of these deaths, an estimated 7.4 million were due to coronary heart disease and 6.7 million were due to stroke. Over three quarters of CVD deaths take place in low- and middle-income countries. Out of the 17 million premature deaths (under the age of 70) due to non-communicable diseases in 2015, 82\% are in low- and middle-income countries, and $37 \%$ are caused by CVDs (WHO, 2017).

So that, cardiac catheterization and coronary artery procedure (angio-

plasty) are two phenomena of medical technology, which have enhanced the lives of millions of patients. The nurse helps the patient undergoing a cardiac catheterization or interventional procedures do not be overwhelmed or frightened by these treatment. They are strongly and comfortably accomplished in thousands on a daily basis in hospitals. So most patients waiting for cardiac catheterization needed adequate data about the technique and this made them worried and anxious.

\subsection{Aim of the study}

Aim of the study was to evaluate the effect of a construction educational protocol on nurses' knowledge, performance and its effect on patient satisfaction undergoing cardiac catheterization.

\subsection{Hypothesis of the study}

1) There are improvements of nurses' knowledge post educational protocol than pre educational protocol.

2) There are improvements of nurses' performance post educational protocol than pre educational protocol.

3) There are high levels of patients`satisfaction after implementation of the educational protocol.

\section{Subjects and methods}

\subsection{Research design a quasi-experimental research de- sign was used to conduct this study}

\subsection{Setting}

This study was conducted at cardiac catheterization, intensive care cardiac care and emergency units at general Port Said hospital in Port Said city - Egypt.

\subsection{Subject}

The researchers used a purposive sample to select nurse's participants; 51 nurses were worked in those departments included in the study and all patients admitted to cardiac catheterization for 6 month. Patients with serious conditions and mental health problems, less than 18 years of age or over 70 years of age were excluded.

\subsection{Tool of data collection}

\subsubsection{The study instruments}

For the purpose of the present study, the questionnaire was used before and after conducting a special educational protocol designed. Two tools were utilized by the researchers to collect the necessary data. These tools were as following:

\subsubsection{Tool I}

For nurses. It consists of three parts as the following:

Part I: Socio-demographic data of the nurses was comprised of items related to nurse age, educational qualification, training courses and duration of experience.

Part II: Nurses' knowledge about cardiac catheterization (Safwat, et al 1993). It was used to determine the nurse knowledge regarding cardiac catheterization patients care that composed of 46 questions. It was concerned with items in order to assess patients cardiac catheterization related knowledge that includes items such as definition of catheterization, causes, sites of catheter entry, number of fasting hours before the procedure, medication, investigation before the procedure, type of anesthesia and time of the procedure, position after the procedure, movement after the procedure, frequency of measuring vital signs, nutrition, health education, prevention of complication methods of urination, post procedure complication and management of the complications.Scoring system: - multiple choice (18 questions) and true and false were 28 question with each right answer was given one score and the wrong answer code was (0) this to assess nurses knowledge. While those who obtained score $<60 \%$ were considered having unsatisfactory nurse in knowledge and satisfactory score of $\geq 60$ percentage.

Part III: Observation Checklist for Nurses Caring for patients undergoing cardiac catheterization.

This tool adapted from (Safwat et al., 1993) that used to assess nurses performance. It consists of 31 items for three domains to investigate performance of nurse before, during and after cardiac catheterization procedure that explain the purpose of procedure, identify allergies, obtain consent, vital signs, take weight, preparation for procedure, dressing to puncture, peripheral pulses and signs and symptoms of clot. Scoring system: each items have three point Likert scale used to assess nurses` performance, 1 indicate done correctly, 0 indicate done incorrectly and not done. While, adequate performance level was considered at score of $\geq 60 \%$ and inadequate performance level at $<60 \%$.

Tool II: For patient (It composed of two parts as following):

Part I: patient socio demographic data. It consists of age, gender, occupation and social status

Part II: patient satisfaction survey was adopted by (Salah et al., 2006) and modified by the researchers. It composes of statements (items) about patient satisfaction related to care before, during and post cardiac catheterization procedure. It includes communication, procedure explanation, patients are asked to provide a response to this statement.

Scoring system: a 5-point Likert scale include completely satisfaction, somewhat satisfied, neutral, somewhat un- satisfaction, and completely un-satisfaction. These will respectively score 5,4,3,2 and 1 .While, higher scores indicate greater satisfaction with the procedure is $\geq 60$ percentage and the lower scores $<60 \%$ indicate un-satisfaction with the procedure. Reliability was assessed by Cronbach's alpha coefficient (0.75).

\subsection{Pilot study}


Was performed on $10 \%$ of patients for testing applicability, feasibility and clarity of tools. No presence changes were done, so the $10 \%$ of study sample were included in the study.

\subsection{Construction educational protocol about cardiac catheterization}

It was consist of knowledge and performance regarding nursing role for caring patients undergoing cardiac catheterization. The researchers requested nurses to answer the pre/post questionnaire (tool I) to assess sociodemographic data, knowledge (part II) and performance of nurses through observational checklist (part III) before apply educational protocol.

\subsubsection{Educational protocol}

It consists of one session every week for 4 weeks to nurses. Each session took 30-45 minute in addition to 15-20 minutes to discuss any questions for nurses. Nurses were allocated into small groups (each group contained [3-5] nurses) to ensure assembly of patients care. After there, the contents of the educational protocol was given to the nurses after assessment knowledge and observe their performance and explain any queries with them through booklet. Then nurses` knowledge and performance were assessed immediately af ter educational protocol. Finally assess for patient satisfaction after educational protocol implementation for nurses to investigate the level of patient satisfaction before, during and after cardiac catheterization procedure.

\subsection{Ethical consideration}

An officially letter from the faculty of nursing was send to accountable authorities of the hospital and approval was attained to conduct this study after explanation of the aim of the study.

Formal consent was taken from the nurses and patients to participate in the study. The researchers firstly introduced themselves to all potential subjects, then explaining the purpose of the study and they were assured that all data collected would be very confidential and only will be used for the study' aim. The researchers stressed that contribution in the study is entirely volunteer and anonymity of the nurse and patients were sure through coding data. Subjects were also knowledgeable that rejection to participate in the study would not disturb their care.

\subsection{Statistical analysis}

The raw data were coded and entered into SPSS system files (SPSS package version 20, Chicago, USA). Analysis and interpretation of data were conducted. The following statistical measures were used: Descriptive statistics including frequency, distribution, mean and standard deviation were used to describe different characteristics.
Univariate analyses including: Mc Nemar test was used to test the significance of results of paired qualitative variables. Moreover, correlation between knowledge and performance scores of nurses with the score of patient satisfaction post educational protocol. The correlation was done using Pearson correlation coefficient. The significance of the results was at the $5 \%$ level of significance.

\section{Results}

Table (1) Shows that the majority of the age sample was $30<40$ years and most of them were diploma nurse. Regarding years of experience $45.1 \%$ of them having $10 \geq$ years of experience. While $84.32 \%$ of them did not receive any training courses

Table (2) this table illustrates knowledge score of nurses' regarding management of patients with cardiac catheterization patient's pre and post educational protocol. It shows that there is only statistical significant difference between nurses' knowledge regarding heath education and prevention of complication. Also, the table indicates that satisfactory nurses' knowledge in all domains of care at post than pre implementation educational protocol.

Table (3) Indicates that the majority of the nurses have adequate performance level in post than pre implementation educational protocol in all domains of care. In addition, the table reflects that statistical significant differences of performance score of nurses' regarding management of patients with cardiac catheterization pre and post educational protocol.

Table (4): Says that positive correlation between nurse's performance during, after cardiac catheterization and knowledge score regarding management of patients with cardiac catheterization pre and post educational protocol. In addition, there is a negative correlation between total performance score and knowledge score with no statistical significant differences at pre and post educational protocol.

Table (5) Shows that $50 \%$ of the patients age between $(30<40)$ years, and $89.6 \%$ were females, $52.9 \%$ of them married. Also it views that most of patients are employed.

Table (6): Represents the level of patient satisfaction regarding cardiac catheterization procedure. This table reveals that the majority of patients were highly satisfaction toward nursing care before, during and after cardiac catheterization procedure.

Table (7): this table illustrates strong positive correlation between nurses' knowledge and patient satisfaction at post educational protocol with statistical significant differences. In addition, the table shows that negative correlation between nurses' performance and patient satisfaction at post educational protocol with no statistical significant difference. Significance: P-vale for Mc Nemar test *significant at $\mathrm{P} \leq 0.05$

R: Pearson correlation coefficient Satisfaction ( $\geq 60$ percentage) Unsatisfaction $(<60 \%)$

Table 1: Socio-Demographic Characteristics of the Studied Nurses

\begin{tabular}{lll}
\hline Socio-demographic characteristics & Studied nurses $(\mathrm{n}=51)$ & $\%$ \\
& No. & 43.1 \\
Age (years) & & 45.1 \\
$20<30$ & 22 & 11.8 \\
$30<40$ & 23 & \\
$40<50$ & 6 & \\
Min-Max & $24.0-47.0$ & 82.33 \\
Mean \pm SD & $31.6 \pm 5.7$ & 17.67 \\
Educational qualifications & & 15.68 \\
Diploma nurse & 42 & 84.32 \\
Bachelor & 9 & 15.7 \\
Training courses & & 39.2 \\
Yes & 8 & 45.1 \\
No & 43 & \\
Duration of experience (years) & & \\
$1<5$ & 8 & \\
$5<10$ & 20 & \\
$\geq 10$ & 23 & $1.0-22.0$ \\
Min-Max & $5.4 \pm 3.8$ & \\
Mean \pm SD & & \\
\hline
\end{tabular}


Table 2: Number \&Percentage of the Knowledge Score of Nurses' Regarding Management of Patients with Cardiac Catheterization Pre and Post Educational Protocol $(\mathrm{N}=51)$

\begin{tabular}{|c|c|c|c|c|c|}
\hline \multirow[t]{3}{*}{ Knowledge of nurses about cardiac catheterization } & \multicolumn{4}{|c|}{ Studied nurses $(\mathrm{n}=51)$} & \multirow[t]{2}{*}{ p- value } \\
\hline & Pre & & Post & & \\
\hline & No. & $\%$ & No. & $\%$ & \\
\hline \multicolumn{6}{|l|}{ Total knowledge score } \\
\hline Unsatisfactory & 3 & 5.9 & 0 & 0.0 & 0.250 \\
\hline Satisfactory & 48 & 94.1 & 50 & 98.0 & \\
\hline \multicolumn{6}{|l|}{ Domains of knowledge } \\
\hline Unsatisfactory & 3 & 5.9 & 1 & 2.0 & 0.625 \\
\hline $\begin{array}{l}\text { Satisfactory } \\
\text { 2) During procedure care }\end{array}$ & 48 & 94.1 & 48 & 94.1 & \\
\hline Unsatisfactory & 5 & 9.8 & 3 & 5.9 & 0.687 \\
\hline $\begin{array}{l}\text { Satisfactory } \\
\text { 3) Post procedure care }\end{array}$ & 46 & 90.2 & 48 & 94.1 & \\
\hline Unsatisfactory & 4 & 7.8 & 2 & 3.9 & 0.625 \\
\hline $\begin{array}{l}\text { Satisfactory } \\
\text { 4) Prevention complications }\end{array}$ & 47 & 92.2 & 49 & 96.1 & \\
\hline Unsatisfactory & 9 & 17.6 & 1 & 2.0 & $0.021 *$ \\
\hline $\begin{array}{l}\text { Satisfactory } \\
\text { 5) Health education }\end{array}$ & 42 & 82.4 & 50 & 98.0 & \\
\hline Unsatisfactory & 19 & 37.3 & 9 & 17.6 & $0.021 *$ \\
\hline Satisfactory & 32 & 62.7 & 42 & 82.4 & \\
\hline
\end{tabular}

Table 3: Performance Score of Nurses' Regarding Management of Patients with Cardiac Catheterization Pre and Post Educational Protocol (N= 51)

\begin{tabular}{|c|c|c|c|c|c|}
\hline \multirow[t]{3}{*}{ Performance of nurses about cardiac catheterization } & \multicolumn{4}{|c|}{ Studied nurses $(\mathrm{n}=51)$} & \multirow[t]{3}{*}{ P-value } \\
\hline & Pre & & Post & & \\
\hline & No. & $\%$ & No. & $\%$ & \\
\hline \multicolumn{6}{|l|}{ Total performance score } \\
\hline Inadequate & 47 & 92.2 & 2 & 3.9 & \multirow[t]{2}{*}{$\mathrm{P}<0.0001^{*}$} \\
\hline Adequate & 4 & 7.8 & 49 & 96.1 & \\
\hline \multicolumn{6}{|l|}{ Domains } \\
\hline Total score before cardiac catheterization & & & & & \multirow{3}{*}{$\mathrm{P}<0.0001^{*}$} \\
\hline Inadequate & 29 & 56.9 & 2 & 3.9 & \\
\hline Adequate & 22 & 43.1 & & & \\
\hline \multicolumn{6}{|l|}{ Total score during cardiac catheter } \\
\hline Inadequate & 46 & 90.2 & 5 & 9.8 & \multirow[t]{2}{*}{$\mathrm{P}<0.0001^{*}$} \\
\hline Adequate & 5 & 9.8 & 46 & 90.2 & \\
\hline Total score after cardiac catheter & 29 & 56.9 & 2 & 3.9 & \multirow[b]{2}{*}{$\mathrm{P}<0.0001^{*}$} \\
\hline Inadequate & 22 & 43.1 & 49 & 96.1 & \\
\hline
\end{tabular}

Table 4: Correlation between Nurse's Knowledge and Performance Scores Regarding Nurses' Role in Dealing with Cardiac Catheterization Patient's Pre and Post Educational Protocol

\begin{tabular}{|c|c|c|c|c|}
\hline \multirow[t]{3}{*}{ Performance of nurses about cardiac catheterization } & \multicolumn{4}{|c|}{ Knowledge score of studied nurses $(n=51)$} \\
\hline & pre & & Post & \\
\hline & $\mathrm{r}$ & $\mathrm{P}$ & r & $\mathrm{P}$ \\
\hline \multicolumn{5}{|l|}{ Domain score } \\
\hline 1) Before cardiac catheter & -0.233 & 0.100 & -0.248 & 0.079 \\
\hline 2) During cardiac catheter & 0.030 & 0.836 & -0.120 & 0.402 \\
\hline 3) After cardiac catheter & 0.042 & 0.769 & 0.024 & 0.869 \\
\hline Total performance score & -0.053 & 0.714 & -0.184 & 0.197 \\
\hline
\end{tabular}

Table 5: Socio-Demographic Characteristics of the Studied Cardiac Catheterization Patients

\begin{tabular}{|c|c|c|}
\hline \multirow[t]{2}{*}{ Socio-demographic characteristics } & \multicolumn{2}{|c|}{ Studied patients $(\mathrm{n}=48)$} \\
\hline & No. & $\%$ \\
\hline \multicolumn{3}{|l|}{ Age (years) } \\
\hline Less than 30 & 13 & 27.1 \\
\hline $30<40$ & 24 & 50.0 \\
\hline $40<50$ & 8 & 16.7 \\
\hline $50<60$ & 3 & 6.3 \\
\hline Min-Max & 18.0 & \\
\hline Mean \pm SD & 34.1 & \\
\hline \multicolumn{3}{|l|}{ Gender } \\
\hline Male & 5 & 10.4 \\
\hline Female & 43 & 89.6 \\
\hline \multicolumn{3}{|l|}{ Occupation } \\
\hline Not employed & 23 & 47.9 \\
\hline Retired & 1 & 2.1 \\
\hline Employed & 24 & 50.0 \\
\hline \multicolumn{3}{|l|}{ Social status: } \\
\hline married & 25 & 52.9 \\
\hline single & 19 & 39.58 \\
\hline widow & 4 & 8.33 \\
\hline
\end{tabular}


Table 6: Number and Percent of Patient Satisfaction Level Regarding Cardiac Catheterization Procedure

\begin{tabular}{|c|c|c|}
\hline \multirow[t]{2}{*}{ Patient satisfaction } & \multicolumn{2}{|c|}{ Studied patients $(n=48)$} \\
\hline & No. & $\%$ \\
\hline \multicolumn{3}{|l|}{ Before procedure } \\
\hline Un-satisfaction & 1 & 2.1 \\
\hline Satisfaction & 47 & 97.9 \\
\hline \multicolumn{3}{|l|}{ During procedure } \\
\hline Un-satisfaction & 1 & 2.1 \\
\hline Satisfaction & 47 & 97.9 \\
\hline \multicolumn{3}{|l|}{ After procedure } \\
\hline Un-satisfaction & 2 & 4.2 \\
\hline Satisfaction & 46 & 95.8 \\
\hline \multicolumn{3}{|c|}{ Total satisfaction score } \\
\hline Un-satisfaction & 2 & 4.2 \\
\hline Satisfaction & 46 & 95.8 \\
\hline
\end{tabular}

Table 7: Correlation between Total Scores of Nurses' Knowledge and Performance Regarding Management of Patients with Cardiac Catheterization and Total Score of Patient Satisfaction at Post Education Protocol

\begin{tabular}{|c|c|c|c|c|}
\hline \multicolumn{5}{|c|}{ Score post educational protocol } \\
\hline & Knowl & & perform & \\
\hline & $\mathrm{r}$ & $\mathrm{P}$ & $\mathrm{r}$ & $\mathrm{P}$ \\
\hline Satisfaction patients score & 0.366 & $0.011^{*}$ & -0.103 & 0.487 \\
\hline
\end{tabular}

R: Pearson correlation coefficient *significant at $\mathrm{P} \leq 0.05$

\section{Discussion}

Nursing role is essential in resolve and prevents the patients from post cardiac catheterization problems. Therefore, the capability of nurses about performance and knowledge regarding patient care after cardiac catheterization is very crucial. The current study is strength to evaluate the effect of a construction educational protocol on nurses' knowledge and performance and its effect on patient satisfaction undergoing cardiac catheterization.

This study presented that most of nurses were $30<40$ years. This result of view" may be related to that age can be reflected as an age of equilibrium in which the person have profession in decision and develops more adaptation and alert to challenges. In addition to performance during providing of medical treatment, they become high aware of the effect of medical care on the patients; sensitive to their anxious honestly interpret medical actions and predictable outcomes (Maville \& Huerta, 2012).

While, concerning educational qualification of the studied sample the results reflected that the majority of the nurses had diploma These findings were disagreement with that of a study conducted by (Hassan \& Aburaghif (2016), Rushdy et al., (2016) found that most level of education were institute of nursing and bachelor nursing degree. While the majority of the study sample having $10 \geq$ years of experience and most of them have not training educational protocol courses $(84.32 \%)$. This findings consistent with the results of many studies by Abdel Halim (2006), Zaki (2010), Hassan \& Aburaghif (2016) who showed that the highest percentage of years' experience were between one to ten years.

Also, the study illustrated that the nurses' satisfactory knowledge in all domains of care at post than pre implementation educational protocol. This findings were supported by (Shini et al., 2018) who reported that the mean score of knowledge after educational protocol higher than mean score before educational protocol in total knowledge regarding the management of patients with coronary angioplasty. It was anecdotal that the implementation of the teaching had effect on knowledge of staff nurses. Also, Abdel-Mowla et al. 2017 found that all nurses post application of the nursing educational brochure were having satisfactory level of knowledge (100\%) with statistically significant difference after one month of the intervention. The reasons for lack of knowledge before catheterization may be correlated with lack of persistent teaching educational protocols or discuss about this therapeutic management, direction, continuous assessment of nurses' performance, and collaboration between all health care team members (nurses - physicians) Rushdy et al.,(2010). In the same line, Isherstha (2013) reported that the mean knowledge score was 14.75 in the pre educational protocol while after educational protocol the score was improved to $16.80 \%$ with statistical significant difference between the pre and post educational protocol.

Also, the study result reflected the majority of the nurses have adequate performance level in post than pre implementation educational protocol in all domains of care. This finding was supported by Shini et al., (2018), Abdelmowla et al., (2017) who identified that the nursing care protocol was establish to be good influence in improving the performance amongst nurses regarding the management of patients undergoing coronary angioplasty. In addition the majority of nurses having satisfactory level of performance following application of the nursing educational protocol were statistically significant differences before and after educational protocol in all items. In the same line (Elewa et al., 2017, Abdelmowla et al., 2017) indicated that the majority of the staff nurses were having improvement performance in post than pre educational protocol .

The study result indicated that positive correlation between nurses performance during, after cardiac catheterization and nurse's knowledge score regarding management of patients with cardiac catheterization pre and post educational protocol. This result agreed with (Feroze et al., 2017) reported that there was positive correlation between knowledge and practice post cardiac catheterization. Regarding patient sample the finding indicated that the majority of patients are employed. This result disagreement with Shinde and Kapurkar (2014) revealed that most study subjects are unemployed. Also, the result reflected that half of the patients sample age are between $(30<40)$ years. This result contradicted with (Sahib \& Mohammad,2016, Oliveira-Filho et al., 2012, Jung et al., 2009, Rastogi et al., 2004) found that the majority of the study patients within age group (55-65) years old. They indicated that the reason due to alterations of the blood vessels and heart that occur with elderly such as the reduction in elasticity of the blood vessels and the capability to respond to variations in compliance of artery wall that excess the effort needed to drive the blood to the many organs of the body due to subsequent rise in the fight to the pumping action of the heart.

Concerning to the study subjects gender, the results indicate, that the higher percentage of the study sample are female. This result disagreement with (Sahib \& Mohammad 2016, Saleem et. al., 2011, Akhtari-Zavare et. al., 2010, Mehta et. al., 2004) found that the highest percentage are male gender differences in the wide possibility of health and illness have been the subject of broad investigation, and are also currently acquisition more attention in nursing.

The current study revealed that half of the studied sampled were married. This is agreement with (Basuny, 2009, Mahgoub et al., 2013) who showed that the highest percentage of the studied sample was married. This may due to the higher level of activities daily life strain on married than single one and that pressure is one of the greatest aggravating features for Coronary artery disease. Together moderate and strong physical and mental events were linked with ischemic. 
While , the result showed the level of patient satisfaction regarding the quality of nursing to cardiac catheterization the majority of patients were satisfied for the care before, during and post cardiac catheterization after the educational protocol. In the same line (Arendts, et al., 2006, Basuny , 2009, Abd Elgaphar (2015) who found that patient satisfaction enhancement after educational protocol. Moreover ,(Keifi et al., 2016 ) mentioned that patient education is one core part of nursing role when its implementation lead to low costs, length of hospital stay, and patient's worry and rises patients' satisfaction with the provided healthcare services. Bastable, 2003 added that patient education can increase patients' satisfaction, improve service quality, reduce patients' anxiety, reduce complications, increase participation in healthcare educational protocols, and increase patients' independence in daily activities. While, Habich et al., 2012 assessed relationship between patients' satisfaction and following clinical guidelines had a positive effect on satisfaction of the patients.

Finally, the study reflected that strong positive correlation between nurses' knowledge and patient satisfaction at post educational protocol with statistical significant differences. So, nurses highly satisfied knowledge lead to increase patient teaching and patients' satisfaction, advance quality service, decrease patients' anxiety, decrease complications, improve participation in healthcare educational protocols, and increase patients' independence in activities of daily These findings consistent with those of others who have recommended that education and communication are among the greatest necessary concerns influencing on patient satisfaction (Arendtsetal., 2006 , Bastable , 2003 ). In addition, many studies consistent for this results have shown that teaching can effectively improve patient knowledge and satisfaction.

Mohammed et al., (2016) added that, patient had no data and knowledge regarding cardiac catheterization and the nursing staff member and medical did not offer them .this cause anxiety and distress from procedure .Many studied mention that the effect of providing information to patients on their anxiety and satisfaction level by (Reed et al, 2008 \& Elsaid, 2010) lead to decreasing patient anxiety and decrease discomfort before cardiac catheterization by education.

\section{Conclusion}

Study findings revealed that there was increase nurses knowledge and performance in the post educational protocol in all domains of care regarding cardiac catheterization. While, majority of patients were satisfied for the nursing care before, during and post cardiac catheterization procedure that rendered by nurses that have educational. Finally, concluded that strong positive correlation between nurses' knowledge and patient satisfaction at post educational protocol with statistical significant differences. Therefore, it can be concluded educational protocol construction plays an important role in increasing nurse's level of performance and effective in patient satisfaction.

\section{Recommendation}

Nurses functioning in cardiac catheterization department should be qualified with augmented knowledge base and hold both interpersonal and technical skills to ensure harmless care. Nurse staff should specifically qualified in the management of cardiac patients along with a subspecialty physician staff to recover the quality care in cardiac catheterization and improve patients` satisfaction with care delivered. Plan for constant educational and training educational protocols occasionally and repeatedly for all health care workers is important.

\section{References}

[1] Abd Elgaphar SM (2015 ): The Effect of Protocol of Nursing Intervention on Quality of Care in Minor Injuries Unit IOSR Journal of
Nursing a nd Health Science (IOSR-JNHS) e-ISSN: 2320-1959.pISSN: 2320-1940 Volume 4, Issue 6 Ver. V (Nov. - Dec.), PP 12-18 www.iosrjournals.org.

[2] Abdel HalimME, (2006): Evaluation of nurses practices toward patients who undergo cardiac catheterization,Sci .J. Nursing, Vol.19 No. 2, P.P1-10.

[3] Abdelmowla R A, Sayed SY and Abo Elmagd NS (2017): Lumbar Puncture: Nurses` Knowledge, Performanceand Patients' Satisfaction with Nursing Care. American Journal of Nursing Science. Vol. 6, No. 5, pp. 433-439. https://doi.org/10.11648/j.ains.20170605.18.

[4] Ahmed Mohamed I. (2015): Predictors of Post -Cardiac Catheterization Femoral Artery Hematoma and Bleeding. Journal of American Science; 11(3):16-22. http://www.jofamericanscience.org

[5] Akhtari-Zavare M, Abdullah MY, Hassan ST, Said SB, Kamali M. (2010): "Patient satisfaction: evaluating nursing care for patients hospitalized with cancer in Tehran Teaching Hospitals, Iran." Global journal of health Science. Apr 1; two (1): P. 117.

[6] Al Sharif BF. (2008): "Patients' satisfaction with hospital services at Nablus District, West bank, Palestine." Master of public health, Faculty of Graduate Studies, at An-Najah.

[7] Arendts, G., MacKenzie, J. and Lee, J (2006) Discharge planning and patient satisfaction in an emergency short-stay unit. Emergency Medicine Australasia, 18(1), 7-14. https://doi.org/10.1111/j.17426723.2006.00798.x.

[8] Arendts, G., MacKenzie, J. and Lee, J. (2006), Discharge planning and patient satisfaction in an emergency short-stay unit. Emergency Medicine Australasia, 18(1), 7-14. https://doi.org/10.1111/j.17426723.2006.00798.x.

[9] Ayral X., Gicquere C.Duhalde a Boucheny D and Dougados M (2002): Effects of video information on preoperative anxiety level and tolerability of joint lavage in knee osteoarthritis. Arthritis and Rheumatism, 47 (4): 380-382. https://doi.org/10.1002/art.10559.

[10] Bastable SB, (2003): Nurse as Educator: Principles of Teaching and Learning for Nursing Practice. Boston: Jones and Bartlett.

[11] BASUNY S (2009) The effect of positioning changing post coronary angiography on patient, outcomes, Master thesis, Faculty of Nursing, Alexandria University

[12] CHAIR S. Y., LI K.M. and WONG S.W (2004): Factors that affect back pain among Hong Kong Chinese patients after cardiac catheterization. European Journal of Cardiovascular Nursing, 3: 279-285. https://doi.org/10.1016/j.ejcnurse.2004.10.001.

[13] Dakheel, F. I. Smko, and R. \& Negrat, K. (2011): Using Data Mining Techniques for Finding Cardiac Outlier Patients. Engineering and Technology, Vol. 73, pp. 442-447.

[14] Dayasiri MB, Lekamge EL. (2010): "Predictors of patient satisfaction with quality of health care in Asian hospitals." Australasian Medical Journal. Nov 13 (11): p. 739-44.

[15] El said H. (2010): Developing nursing care guidelines for patients undergoing to cardiac catheterization based on their needs. Master Thesis, Faculty of Nursing, Alexandria University.

[16] ElewaA' Elshahed B and ElkattanA (2017): Effect of an Educational Educational protocol on Improving Quality of Nursing Care of Patients with Thalassemia Major as Regards Blood Transfusion. American Journal of Nursing Research Vol. 5, No. 1, pp 13-21. https://doi.org/10.12691/ajnr-5-1-2.

[17] Feroze M*, Afzal M, Sarwar H , Galani A and Afshan S ( 2017): Knowledge and Performanceof Registered Nurses about Patient Safety after Cardiac Catheterization in Punjab Institute of Cardiology Hospital in Lahore, Pakistan. International Journal of Musculoskeletal Pain prevention Volume 2, Number 2, spring.

[18] Feroze M, Afzal M, Sarwar H, Galani A, Afshan S.(2017): Knowledge and Practice of Registered Nurses about Patient Safety after Cardiac Catheterization in Punjab Institute of Cardiology Hospital in Lahore, Pakistan. IJMPP. 2 (2):233-238.

[19] Habich M, Wilson D, Thielk D, Melles GL, Crumlett HS, Masterton $\mathrm{J}$, et al (2012): Evaluating the effectiveness of pediatric pain management guidelines. J Pediatric Nurs.27 (4): 336-345. https://doi.org/10.1016/j.pedn.2011.06.002.

[20] Hassan NK. In addition, AburaghifLA (2016): Effectiveness of an Educational Educational protocol on Nurse's knowledge concerning Complications of Cardiac Catheterization among Children at $\mathrm{Al}-$ Nassirhya Heart Center. KUFA JOURNAL FOR NURSING SCIENCES Vol. 6 No. 3 Sep. through Dec.

[21] Jamshidi N, Abbaszadeh A. and Kalyani M.N. (2009): Effects of video information on anxiety, stress and depres-sion of patients undergoing coronary amigo.

[22] JUNG U., TORREJON C. and TIGH A. (1992): N-3 fatty acids and cardiovascular diseease: Mechanism underling beneficial effects. The American J. of Clinical Nutrition, 87: -1499, 2009. 
[23] Keifi S, Shahriari M, Baghersad Z, Sheibani- Tehrani D and Rejalian F (2016): Effects of Patient Education Educational protocol on the Quality of Nursing Care and Inpatient Satisfaction in Surgical Wards of Selected Hospitals in Isfahan, Iran. Hosp Pract Res. Dec 1(4):129134 https://doi.org/10.21859/hpr-0104129.

[24] Kern MJ. (2011): The cardiac catheterization handbook. Fifth edition. Printed in China: saunders Elsevier;: P.P. 1-4.

[25] Mahdi M. and Mohammad S. (2016): Cardiac Catheterization Patients Satisfaction towards Health Care Services Provided At Cardiac Center in AL-Najaf AL-Ashraf Governorate. International Journal of Scientific and Research Publications, Volume 6, Issue 9, September: 518- 529 www.ijsrp.org.

[26] Mahgoub A Mohamed W, Mohamed M Abelaziz M, and Kishk Y (2013) Impact of Knowledge about Early Ambulation on Patients' Satisfaction Post Percutaneous Coronary Intervention, at Assiut University Hospital Med. J. Cairo Univ., Vol. 81, No. 2, December: 97 104, www.medicaljournalofcairouniversity.net.

[27] Maville, J., \& Huerta, C. (2012): Health Promotion in Nursing: Cengage Learning, 223.

[28] Mehta RH, Montoye CK, Faul J, Nagle DJ, Kure J, Raj E, Fattal P, Sharrif S, Amlani M, Changezi HU, Skorcz S. (2004): "Enhancing quality of care for acute myocardial infarction: shifting the focus of improvement from key indicators to process of care and tool use: the American College of Cardiology Acute Myocardial Infarction Guidelines Applied in PerformanceProject in Michigan: Flint and Saginaw Expansion." Journal of the American College of Cardiology. (Third Ed). Jun 1643 (12): P.P. 2166-73.

[29] Mohammed G1. Mohammed Z, Al-Araby H (2016) :Impact Of Designed Nursing Educational Protocol On Health Promotion For Patients Undergoing Coronary Artery Stent Outcome IOSR Journal of Nursing and Health Science (IOSR-JNHS) e-ISSN: 2320-1959.pISSN: 2320-1940 Volume 5, Issue 2 Ver. VI (Mar. - Apr.), PP 54-63 www.iosriournals.org.

[30] Mohammed. H Said H and Salah M (2013): Determining Best Nursing Practice: Effectiveness of Three Groin Compression Methods Following Cardiac Catheterization. Journal of American Science 9(6): 274- 285. http://www.jofamericanscience.org.

[31] Moradi T, Adib-Hajbaghery M. (2015): The Effect of a Multi-Modal Preparation Package on Anxiety in Patients Undergoing Coronary Angiography. International Cardivascular Research Journal. Jan; 9 (1): p.p. $10-16$

[32] Mosby DL , Manierre MJ , Martin SS , Kolm P , Abuzaid AS Jurkovitz CT, Elliott DJ , Weintraub WS,(2018): Patient Satisfaction with Care After Coronary Revascularization.Apr;11(2):217-223. doi: 10.1007/s40271-017-0274-4. National University, Nablus, Palestine. AL- Najaf National University, 2008: P. 1.

[33] Oliveira-Filho AD, Barreto-Filho JA, Neves SJ, Lyra Junior DP (2012): "Association between the 8-item Morisky Medication Adherence Scale (MMAS-8) and blood pressure control." Arquivosbrasileiros de cardiologia. Jul 99 (1): P.P. 649-58.

[34] Philipe E., Meney M. , Larrazet F., Ben -AB - Derrazak F., Dibie A., Mezianet aaaaaaat., et al ., (2006): Effects of video information in patients undergoing coronary angiography. Archives des Maladies du Coeur ET des Vaisseaux, 99 (2): 95-101.

[35] Rastogi T, Reddy KS, Vaz M, Spiegelman D, Prabhakaran D, Willett WC, Stampfer MJ, Ascherio A. (2004): "Diet and risk of ischemic heart disease in India. The American journal of clinical nutrition." Apr 179 (4): P.P. 582-92. https://doi.org/10.1093/ajcn/79.4.582.

[36] Reed FS, Blake G, \& Ohno-Machado L. (2008) vascular closure devices and the risk of vascular complications after percutaneous coronary intervention in patients receiving glycoprotein IIb-IIIa inhibitors. Am J Cardiol; 88:493-496

[37] Ruffinengo C. Versino E and Renga G (2009): Effectiveness of an informative video on reducing anxiety levels in patients undergoing elective coronarography: An RCT. European Journal of Cardiovascular Nursing, 8: 57-61. https://doi.org/10.1016/j.ejcnurse.2008.04.002.

[38] Rushdy T I, Morsy W Y and Elfeky H A (2016) Nurses' knowledge and performance regarding care of patients connected to intra- aortic balloon pump at Cairo university hospitals .Egyptian nursing journal elmagla.egy2010@yahoo.com.

[39] Safwat, A., El-Sherbiny, M., and El-Senousy, T.; (1993): Assessment of Knowledge and Performance of Nurses Working with Patients undergoing Cardiac Catheterization in Ain Shams University Hospitals

[40] Sahib MM and Mohammad SJ (2016 ):Health Care Services Provided At Cardiac Center in ALNajaf AL-Ashraf Governorate., International Journal of Scientific and Research Publications, Volume 6 , Issue 9, September 526 ISSN 2250-3153.
[41] Saleem F, Hassali MA, Shafie AA, Awad AG, Bashir S. (2011): "Association between knowledge and drug adherence in patients with hypertension in Quetta, Pakistan." Tropical Journal of Pharmaceuti$\begin{array}{llllll}\text { cal Research. Apr } 1 & 10 & \text { (2): } & \text { P.P. } & 125-132 .\end{array}$ https://doi.org/10.4314/tjpr.v10i2.66552.

[42] Samira E. Aboalizm, Nahid F. El Gahsh, Samah E. Masry (2016)Effect of Early Nursing Preparation on Anxiety Among Patients Undergoing Cardiac Catheterization. American Journal of Nursing Science. 5(5): 222-231 https://doi.org/10.11648/j.ajns.20160505.17.

[43] Sherstha R (2013): Impact of educational intervention on nurses knowledge regarding care of patients with cental venous line. .journal of kathmandu medical college vol, 2, No, 1, Issue3 Jan-march.

[44] Shinde M, Kapurkar K. (2014): "Patient's Satisfaction with Nursing Care Provided in Selected Areas of Tertiary Care Hospital." International Journal of Science and Research. Feb 3 (2): P. 150-151-152161.

[45] Shini S L, Laly Paul, Smitha P V (2018): Effectiveness of nursing care protocol on knowledge and performanceamong staff nurses regarding management of patients undergoing coronary angioplasty .GJRA - journal for research analysis. Volume 7, issue 1, January , issue N, 2277-81-60

[46] Steffemimo G., Viada E., Marwngo and Ca-nale R (2007): Effectiveness of video-based patient information before percutaneous cardiac interventions. Journal of Cardiovascular Medicine, 8 (5): 20-33.

[47] Wenger N.K (1992): Patient and family education and counsel ing: A requisite component of cardiac rehabilitation. In Mathes P., Halhuber M.J., editors. Controversies in car diac rehabilitation. Berlin: Springer-Verlag.

[48] WHO Cardiovascular disease. World Health Organization; (2013). [Cited accessed August 28, Available from: http: //www.who. int/cardiovasculardiseases/en/index.html.

[49] WHO. (2017): Cardiovascular disease. World Health Organization.; Available from: http://www.who.int/cardiovascular_diseases/en/.

[50] Zaki S.M , (2010): Evaluation of Nurses' Practices toward Children undergoing Cardiac Catheterization,Iraqi Scientific Nursing Journal, , Vol. 23, No(2), P.P 83-90. 